\title{
Cosmetic Habits and Cosmetic Contact Dermatitis in Children
}

\section{An Goossens, R. Pharm, PhD}

\author{
Address \\ Department of Dermatology, University Hospital K.U. Leuven, Kapucijnenvoer 33, \\ 3000 , Leuven, Belgium \\ Email:an.goossens@uzleuven.be
}

Published online: 6 June 2015

(C) Springer International Publishing AG 2015

\section{This article is part of the Topical Collection on Pediatric Allergy}

Keywords Allergic contact dermatitis - Cosmetics - Children - Fragrances - Hair dyes . Herbal - Methylisothiazolinone - Natural $\cdot$ para-Phenylenediamine - Preservatives .

Safety requirements . Sunscreens . Temporary henna tattoos

\begin{abstract}
Allergic contact dermatitis from cosmetics in children and adolescents has recently become more frequently observed and recognized. Fragrances, hair dyes, sunscreen agents, and preservative agents, particularly methylisothiazolinone, are the most frequently reported contact allergens.
\end{abstract}

\section{Introduction}

Although there are only few large epidemiological studies on contact-allergic reactions in children, recent studies $[1 \bullet, 2,3]$ have shown that such reactions are frequent, with similar findings both in atopic and non-atopic subjects. Moreover, cosmetic products are increasingly recognized as the main allergenic culprits. Indeed, the market for cosmetic products, especially formulated for children, is still expanding and habits common for adults such as going to "beauty farms" are becoming adapted for this young age group as well. Consequently, one can expect cosmetics to become even more important causes of allergic contact dermatitis in the future [4]. Besides, children may also become allergic to cosmetics used by the mother (or the person taking care of them), so-called con- sort or "by proxy" dermatitis, of which numerous examples have been reported in the literature (e.g., [4]).

Generally, no extra safety requirements for products intended for children are required, except for a few cosmetics for which the use is restricted, as in the case of hair colorants containing paraphenylenediamine and derivatives that, because of their strong sensitization potential, cannot be used in children under the age of 16 . Certain cosmetic ingredients are also restricted because of other health concerns; for example, the preservative agent iodopropynyl butylcarbamate, due its iodine content, is not to be used in children under the age of 3 (http://ec.europa.eu/consumers/cosmetics/ cosing/). 


\section{Cosmetic ingredients responsible for allergic contact dermatitis in children}

Almost all cosmetic ingredients may be responsible for allergic contact dermatitis [4]. Emulsifiers and other vehicle compounds, such as wool alcohols (lanolin), are possible allergenic culprits in cosmetics [1 $\bullet$ ]; however, fragrance components (fragrance mix, myroxylon pereirae, and colophonium), hair dye chemicals, and preservative agents are certainly the most important allergens $[1 \bullet, 2,3]$. In recent years, also, sunscreen agents have gained attention in this regard, and as the use of herbal preparations and "natural" products is dramatically increasing, contact allergy to ingredients in them is more frequently observed as well.

\section{The main contact allergens in children}

\section{- Fragrances}

The markers for fragrance allergy in the baseline series are the following: fragrance mix I, which contains eight perfume components, i.e., amyl cinnamal, cinnamal, cinnamyl alcohol, hydroxycitronellal, eugenol, isoeugenol, geraniol, and Evernia prunastri (oakmoss) extract, all diluted $1 \%$ in petrolatum and emulsified with sorbitan sesquioleate; fragrance mix II consisting of alpha-hexyl cinnamal $5 \%$, hydroxyisohexyl 3-cyclohexene carboxaldehyde (Lyral ${ }^{\circledR}$ ), farnesol and coumarin $5 \%$, citral $1 \%$, and citronellol $0.5 \%$, as well as hydroxyisohexyl 3-cyclohexene carboxaldehyde separately $5 \%$, all in petrolatum, respectively; myroxylon pereirae; and, to a certain extent, also colophonium [5]. Because of the increasing importance of fragrance allergy and to ensure that sensitized consumers are adequately informed, 26 fragrance components are (since March 2005) to be labeled as cosmetic ingredients on the packaging (Annex 3 of the Cosmetic Directive 2003/15/EC). Although guidelines for the maximum concentration of fragrances (and preservatives) in cosmetics have been provided, it has been previously demonstrated that, for example, cosmetic "toys" may contain much higher concentrations of fragrances [6].

Fragrance components are not necessarily allergenic as such, but may sometimes form sensitizing components on exposure to air, such as in the case of limonene and linalool that are widely used not only in cosmetics but also in household (detergents) and industrial (degreasers) products; they are referred to as prehaptens. Their hydroperoxides are strong allergens [7, 8]. Occasionally, cross-reactions are seen to botanically derived materials, such as plants from the Compositae family, due to the common presence of oxidized terpenes [9] (cf. below).

- Preservatives

For preservatives, shifts have occurred over the years [10]. In recent years, cosmetic products have created a worldwide epidemic of contact-allergic reactions due to the presence of methylisothiazolinone (MI), in particular, both in leave-on and also rinse-off products [11, 12]. MI is not only a weaker sensitizer than the chlorinated derivative methylchloroisothiazolinone (MCI) but also 
less efficient as a preservative; hence, larger use concentrations (up to $100 \mathrm{ppm}$ ) than the mixture MCI/MI (max. $15 \mathrm{ppm}$ ) are admitted. Initially, most cases were due to the use of wet wipes (moist toilet paper) for intimate hygiene, also for babies [13], which were sometimes responsible for hand dermatitis in their parents as well; later on, leave-on products, such as various skin-care products, sunscreens, and deodorants, but also rinse-off products, such as shampoos and liquid soaps, turned out to be important sensitization sources (e.g., [14•]). MI has sometimes been responsible for severe skin lesions and atypical clinical symptoms, also in children, which may lead to a delay in the correct diagnosis (e.g., [15]).

Moreover, regarding the frequency of positive reactions observed, the studies carried out have even underestimated the true MI epidemic because patch tests were not always conducted with the most optimal test concentrations. Indeed, in order to correctly diagnose contact allergy caused by MCI and MI, it is of utmost importance to include in the European baseline series MCI/MI 200 ppm (instead of $100 \mathrm{ppm}$ ) and preferably 2000 ppm instead of MI 200 or 500 ppm (as was previously the case), using a micropipette for application [16, 17]. The cosmetic industry already advised its members to phase out the use of MI in leave-on products, and the European authorities should urgently regulate this, as is the case for the presently allowed mixture of MCI/MI (Official Journal of the European Union 26.9.2014, L281/1-4. COMMISSION REGULATION (EU) No 1003/2014 of 18 September 2014 amending Annex V to Regulation (EC) No 1223/2009 of the European Parliament and of the Council on cosmetic products). Indeed, from 16 July 2015, only cosmetic products which comply with this regulation shall be placed and, from 16 April 2016, be made available on the Union market, respectively. However, household (cleansing products) and industrial products, such as paints, should be regulated as well since they are also important sensitization and elicitation sources, the latter being responsible for severe airborne dermatitis (and also systemic symptoms), also in children (e.g., $[13,15])$.

Other preservative agents such as formaldehyde and releasers may occasionally also cause contact dermatitis in baby wipes and other children's cosmetics $[18,19]$, and parabens are only very exceptional allergens in such products [20]. - Hair dyes

Hair dyes are the prime cause of para-phenylenediamine allergy [21] and have been reported as causes of (sometimes) severe dermatitis in children as well $[2,22,23]$, not only in those primarily sensitized by hair dye application but particularly in subjects previously sensitized by temporary henna tattoos, which became very popular in the Western world. In contrast to the body pastes used by Hindus and Muslims, consisting solely of henna, many of them did illegally contain high concentrations (up to $30 \%$ or more!) of para-phenylenediamine (PPD) and derivatives, to let the tattoo dry faster and make it darker and longer acting [24•]. However, the latter chemicals are strong sensitizers in hair dyes of the oxidative (permanent) type (even though the maximum EU permissible concentration is $3 \%$ when applied as a mixture), both in hairdressers (also apprentices) and consumers. According to the Cosmetics Directive in 2013, temporary henna tattoos containing these dyes have been forbidden for application on the skin; however, some illegal uses still continue, especially at festivals and holiday resorts. 
PPD-containing henna tattoos, in contrast to adults in whom the incubation period most often takes 8-12 days after the sensitizing exposure, may in children already elicit contact eczema 4-7 days following primary sensitization, often from the first application. Severe, sometimes generalized, dermatitis and even lichenoid or EEM-like eruptions may develop, and healing may occur with post-inflammatory long-lasting hyper-pigmentation or depigmentation [24•].

When diagnosing contact allergy in these cases, patch testing should be done with caution: the patch test with PPD should be applied during $1 \mathrm{~h}$ only, or with a 10- to 100-fold dilution, in order to avoid extremely strong reactions.

Moreover, PPD does cross-react with many substances present in our environment, such as chemically related hair and textile dyes (often present in synthetic clothing), local anesthetics of the ester type (e.g., benzocaine), sunscreens ( $p$-aminobenzoic acid), and certain plastic and rubber compounds. Thus, the consequences of this illegal practice are serious and may compromise the later career of the sensitized youngsters.

\section{- Sunscreens}

Sunscreens are increasingly used, also in children, and may be responsible for allergic and photoallergic reactions. Particularly, octocrylene, a UV-B sunscreen and a stabilizer [25•], has been reported as a cause of contact allergy in children, in particular $[26,27]$. When photoallergic contact dermatitis from octocrylene (and benzophenones) occurs [27], it is mostly induced by photosensitization to ketoprofen, a non-steroidal anti-inflammatory drug that is very popular in several European countries, such as Belgium, France, Italy, and Spain. It generally occurs only in adults.

But ingredients other than the sunscreen in such products may also be responsible for contact-allergic reactions, such as, for example, ethylhexylglycerin, a skin-conditioning agent with antimicrobial properties [28], and xanthan gum [29], a thickening agent, which were also allergenic culprits in children.

- Natural ingredients

Natural ingredients, such as plant extracts or other natural substances, have become very popular in recent years and may give rise to (sometimes severe) contact dermatitis problems [30, 31]. Examples of allergenic culprits reported in children are argan oil [32], propolis and carnauba wax from lip balm and chewable vitamins [33], fructooligosaccharide [34], and panthenol (a vitamin B derivative) [35].

As mentioned earlier, children may also become allergic to plants, such as those belonging to the Asteraceae or Compositae family [36, 37], the components of which often cross-react to fragrances [9]. Indeed, natural products are complex mixtures of many chemical ingredients, the exact nature of which is, in most cases, not known; they often give rise to multiple positive reactions to different natural products because of common or chemically related ingredients.

Nowadays, skin-care products, especially in those intended to treat dry skin of atopic subjects (often children), often contain potentially sensitizing proteincontaining plant extracts (e.g., from soybean, oat, wheat) or hydrolyzed proteins, in particular. The latter may, besides delayed-type reactions, for example, due to hydrolyzed wheat proteins in a 3-year-old girl [38], also cause IgEmediated contact urticaria. Recently, a 3-year-old atopic boy was described who had probably been sensitized via maternal skin contact ("by proxy") to hydrolyzed wheat protein contained in a moisturizer [39]. With regard to 
percutaneous sensitization, high molecular weight wheat hydrolysates seem to be more allergenic than the lower ones [40]. The use of hydrolyzed proteins thus gives rise to controversies [41-43] since subjects may get sensitized through topical preparations and subsequently develop food allergies.

\section{Conclusion}

Allergic contact dermatitis from cosmetics in children and adolescents has recently become more frequently observed and recognized. Fragrances, hair dyes, sunscreen agents, and preservative agents, particularly methylisothiazolinone, are the most important allergens.

It remains an important task for the cosmetic industry to avoid the main allergens known from the literature and to formulate cosmetics intended to be used in this age group as safely as possible.

\section{Compliance with Ethics Guidelines}

\section{Conflict of Interest}

An Goossens declares the receipt of research grants from several cosmetics companies, in support of the Department of Dermatology at the University Hospital/K.U. Leuven, outside the submitted work.

\section{Human and Animal Rights and Informed Consent}

This article does not contain any studies with human or animal subjects performed by the author.

\section{References and Recommended Reading}

Papers of particular interest, published recently, have been highlighted as:

- Of importance

1. $\quad$ Belloni Fortina A, Cooper SM, Spiewak R, et al. Patch test results in children and adolescents across Europe Analysis of the ESSCA Network 2002-2010. Pediatr Allergy Immunol. 2015. doi:10.1111/pai.12397.

Large multicenter study in Europe.

2. Simonson AB, Deleuran M, Mortz CG, et al. Allergic contact dermatitis in Danish children referred for patch testing - nationwide multicentre study. Contact Dermatitis. 2013;70:104-11.

3. Zug KA, Pham KA, Belsito D, et al. Patch testing in children from 2005 to 2012: results from the North American Contact Dermatitis Group. Dermatitis. 2014;25:345-55.

4. Morren M-A, Goossens A. Contact allergy in children. In: Duus Johansen J, Frosch PJ, Lepoittevin JP, editors. Contact dermatitis chapter 48. 5th ed. Berlin: Springer -Verlag; 2011.
5. Nardelli A, Carbonez A, Drieghe J, Goossens A. Results of patch testing with fragrance mix 1 and 2 and their ingredients, and Myroxylon pereirae and colophonium over a 21-year period. Contact Dermatitis. 2013;68:307-13.

6. Rastogi SC, Johansen JD, Menné T, et al. Contents of fragrance allergens in children's cosmetics and cosmetic-toys. Contact Dermatitis. 1999;41:84-8.

7. Bråred Christensson J, Andersen KE, Bruze M, et al. Positive patch test reactions to oxidized limonene: exposure and relevance. Contact Dermatitis. 2014;71:264-72.

8. Bråred Christensson J, Andersen KE, Bruze M, et al. Air-oxidized linalool-a frequent cause of fragrance contact allergy. Contact Dermatitis. 2012;67:247-59. 
9. Paulsen E, Andersen KE. Colophonium and compositae mix as markers of fragrance allergy: crossreactivity between fragrance terpenes, colophonium and compositae plant extracts. Contact Dermatitis. 2005;53:285-91.

10. Svedman C, Andersen KE, Brandão FM, et al. Followup of the monitored levels of preservative sensitivity in Europe: overview of the years 2001-2008. Contact Dermatitis. 2012;67:312-4.

11. Gonçalo M, Goossens A. Whilst Rome burns: the epidemic of contact allergy to methylisothiazolinone (Editorial). Contact Dermatitis. 2013;68:257-8.

12. Lundov MD, Opstrup MS, Johansen JD. Methylisothiazolinone contact allergy-a growing epidemic. Contact Dermatitis. 2013;69:271-5.

13. Madsen JT, Andersen KE. Airborne allergic contact dermatitis caused by methylisothiazolinone in a child sensitized from wet wipes. Contact Dermatitis. 2014;70:183-4.

14. Aerts O, Baeck M, Constandt L, et al. The dramatic increase in the rate of methylisothiazolinone contact allergy in Belgium: a multicentre study. Contact Dermatitis. 2014;71:41-8.

A good review on senstitization due to methylisothiazolinone.

15. Aerts O, Cattaert N, Lambert J, Goossens A. Airborne and systemic dermatitis, mimicking atopic dermatitis, caused by methylisothiazolinone in a young child. Contact Dermatitis. 2013;68:250-1.

16. Bruze $M$, Engfeldt $M$, Gonçalo $M$, et al. Recommendation to include methylisothiazolinone in the European baseline patch test series-on behalf of the European Society of Contact Dermatitis and the European Environmental and Contact Dermatitis Research Group. Contact Dermatitis. 2013;69:263-70.

17. Bruze M, Goossens A, Isaksson M. Recommendation to increase the test concentration of methylchloroisothiazolinone/methylisothiazolinone in the European baseline patch test series-on behalf of the European Society of Contact Dermatitis and the European Environmental and Contact Dermatitis Research Group. Contact Dermatitis. 2014;71:35-40.

18. Jacob SE, Hsu WE. Sodium hydroxymethylglycinate: a potential formaldehyde-releasing preservative in child products. Dermatitis. 2009;20:347-9.

19. Garca-Gavín J, Gonzáles-Vilas D, Fernández-Redondo $\mathrm{V}$, Toribo J. Allergic contact dermatitis in a girl due to several cosmetics containing diazolidinyl-urea or imidazolidinyl-urea. Contact Dermatitis. 2010;63:49_ 50.

20. Nardelli A, Morren MA, Goossens A. Contact allergy to fragrances and parabens in an atopic baby. Contact Dermatitis. 2009;60:107-9.

21. Sösted H, Rustemeyer T, Gonçalo M, et al. Contact allergy to common ingredients in hair dyes. Contact Dermatitis. 2013;69:32-9.

22. Sösted H, Johansen JD, Andersen KE, Menné T. Severe allergic hair dye reactions in 8 children. Contact Dermatitis. 2006;54:87-91.
23. Gray JE. Severe allergic hair dye reactions in 8 children (letter to the editor). Contact Dermatitis. 2006;55:256.

24. de Groot A. Side-effects of henna and semi-permanent black henna tattoos: a full review. Contact Dermatitis. 2013;69:1-25.

A complete review about temporary henna tattoos.

25. de Groot AC, Roberts DW. Contact and photocontact allergy to octocrylene: a review. Contact Dermatitis. 2014;70:193-204.

Very good review about the sunscreen octocrylene.

26. Dumon D, Dekeuleneer V, Tennstedt D, et al. Allergic contact dermatitis caused by octocrylene (and benzophenone-3) in a young child. Contact Dermatitis. 2012;67:240-2.

27. Avenel-Audran M, Dutartre H, Goossens A, et al. Octocrylene, an emerging photoallergen. Arch Dermatol. 2010;46:753-7.

28. Sasseville D, Moreau L, A-Sowaidi M. Allergic contact dermatitis form ethylhexylglycerin in sunscreens. Dermatitis. 2014;25:42-3.

29. Aerts O, Clinck B, Schramme M, Lambert J. Contact allergy caused by Tinosorb M: let us not forget about xanthan gum. Contact Dermatitis. 2015;72:121-3.

30. Corazza M, Borghi A, Gallo R, et al. Topical botanically derived products: use, skin reactions, and usefulness of patch tests. A multicenter Italian study. Contact Dermatitis. 2014;70:90-7.

31. Jack AR, Norris PL, Storrs FJ. Allergic contact dermatitis to plant extracts in cosmetics. Semin Cutan Med Surg. 2013;32:140-6.

32. Barrientos N, Moreno de Vega M, Dominguez J. Allergic contact dermatitis caused by argan oil in an infant. Contact Dermatitis. 2014;71:316-7.

33. Jacob SE, Chimento S, Castanedo-Tardan MP. Allergic contact dermatitis to propolis and carnauba wax from lip balm and chewable vitamins in a child. Contact Dermatitis. 2008;58:242-3.

34. Vigan M. A case of allergic contact dermatitis caused by fructo oligosaccharide. Contact Dermatitis. 2012;66:111-2.

35. Chin MF, Hughes TM, Stone NM. Allergic contact dermatitis caused by panthenol in a child. Contact Dermatitis. 2013;69:321-2.

36. Flohr C, Ravenscroft J, English J. Compositae dermatitis in three children with hand dermatitis. Contact Dermatitis. 2008;59:370-9.

37. Fortina $\mathrm{AB}$, Romano I, Peserico A. Contact sensitization to compositae mix in children. J Am Acad Dermatol. 2005;53:877-80.

38. Livideanu C, Giordano-Labadie F, Paul C. Contact dermatitis to hydrolysed wheat protein. Contact Dermatitis. 2007;57:283-4.

39. Leheron C, Bourrier T, Albertini M, GiovanniniChami L. Immediate contact urticaria caused by hydrolysed wheat proteins in a child via maternal skin contact sensitization. Contact Dermatitis. 2013;68:379-80. 
40. Chinuki Y, Takahashi H, Dekio I, et al. Higher allergenicity of high molecular weight hydrolysed wheat protein in cosmetics for percutaneous sensitization. Contact Dermatitis. 2013;68:86-93.

41. Pecquet $\mathrm{C}$, Lauriere $\mathrm{M}$, Huet $\mathrm{S}$, Leynadier $\mathrm{F}$. Is the application of cosmetics containing protein-derived products safe? Contact Dermatitis. 2002;46:123.
42. Boussault P, Léauté-Labrèze C, Saubusse E, et al. Oat sensitization in children with atopic dermatitis: prevalence, risks and associated factors. Allergy. 2007;2:1251-6.

43. Goujon-Henry C, Hennino A, Nicolas JF. Letter to the editor. Allergy. 2008;63:782. former paper discussed. 